\title{
DETERMINANTS OF CHOICE OF ASSORTMENT SIZE AT A POINT OF SALE
}

\author{
S. Petrova* \\ Department of Commerce, Faculty of Industry and Commerce, D. A. Tsenov Academy of Economics, \\ Svishtov, Bulgaria
}

\begin{abstract}
Retailers today use highly efficient economic tools that enable them to make appropriate decisions about assortment size. The determinants that assist or restrict a retailer's choice influence largely the overall size of assortment offered. The main purpose of this study is to focus on examining and interpreting basic theoretical-methodological and empirical formulations regarding retailers' strategic choice of assortment size and, on this basis, to distinguish the economic effects manifested at the point of sale. The scientific methods of theoretical and empirical research that are used involve: factor analysis and synthesis, comparison, generalization, induction and deduction, illustration through figures and tables. The outcomes of the study are summarized in the conclusions drawn and relate to outlining retailers' preferences regarding the choice of appropriate assortment size.
\end{abstract}

Keywords: Retailers; Retail assortment; Retailer's assortment decisions.

\section{INTRODUCTION}

Retailers today use strategically economic tools to determine the choice of assortment size. A retailer's highly efficient choice ensures the necessary basis for understanding their own role in the process of forming and offering assortment positions on the retail market.

The main purpose of this study is to examine and interpret basic theoretical-methodological and empirical formulations regarding retailers' strategic choice of assortment size and, on this basis, to distinguish the economic effects manifested at the point of sale.

In order to achieve the goal, the following research tasks have been set: defining and systematizing of basic theoretical formulations about the determinants of choice of assortment size; creating a methodological framework to help investigate the effects of the assortment size on the activities at points of sale; drawing conclusions and making recommendations for improving the formation and supply of a

\footnotetext{
*Correspondence to: $S$. Petrova, Faculty of Industry and Commerce, D. A. Tsenov Academy of Economics, Svishtov, Bulgaria, 2, Emanuil Chakarov Street, 5250, e-mail: s.petrova@unisvishtov.bg, mobile phone: +359886580689
}

certain assortment size by the retailer. In this aspect, the author studies specialized literature and practice related to outcomes presented regarding the nature of the determinants specifying the choice of assortment size in the retail sector on the example of two large retail chains operating on the Bulgarian market "Billa Bulgaria" EOOD and "Kaufland Bulgaria "KD. The use of an appropriate set of data that covers grocery retailers allows distinguishing and characterizing the basic determinants that assist or restrict the creation of certain assortment size. Studying the highlighted determinants helps to identify to a certain extent their effects on the assortment offer activities at points of sale. The scientific methods of theoretical and empirical research that are used include: factor analysis and synthesis, comparison, generalization, induction and deduction, illustration through figures and tables. The outcomes of the theoretical-empirical study are related to outlining retailers' preferences regarding the strategic choice of appropriate assortment size at a point of sale.

\section{THEORETICAL FRAMEWORK OF THE DETERMINANTS OF CHOICE OF ASSORTMENT SIZE}


One of retailers' most important tasks is to choose the number of items comprising their assortment in each commodity line. This task involves optimizing the benefits and costs of the assortment positions offered, affecting the volumes and structures of sales and profits. For this reason, studies conducted by S. Arnold, T. Oom and D. Tigert argue that, from the point of view of retailers, it is particularly important to decide on an increase or decrease in the assortment size and its impact on consumer behaviour towards the retailer, which ultimately predetermines the likelihood of making a purchase (1).This probability is theoretically defined by authors such as Broniarczyk, S., D. Hoyner and L. McAlister (2).

At the end of the $20^{\text {th }}$ and the beginning of the next century a period of studies was formed focusing on retailers' assortment composition and size. This relates to the theoretical and empirical formulations of a group of theoreticians, including B. Kahn, and D. Lehmann, whose research interests focus on the framework for determining the assortment size in the retail sector (10). These theoreticians point out that they do not reach sufficient empirical data to illustrate the way in which the assortment size as well as the whole assortment composition are quantified and planned in practice.

A group of researchers working expertly on the issues so highlighted, led by $E$. Fox, $A$. Montgomery and L. Lodish, argue that retailers should adjust the assortment size offered at points of sale to a number of demographic characteristics and indicators, as well as to the specificities of consumer spending on the local market (7). Besides, some of the theoreticians, such as $A$. Kok and M. Fisher, claim that assortment should be localized, i.e. retailers should decide on common assortment size offered by all the chain stores, with no
PETROVAS. exceptions (11). Thus, the varied and varying consumer requirements are met in a more complete and better way.

In the practice of retail assortment management, there is a need to further develop and enrich the views and empirical formulations of how the decisions about assortment composition and size are formed and made within the points of sale. The answer to the questions of how these decisions are consistent with consumer demand and how they respect the specificities and differences of the different retail formats are important, as well as the manifested degree of competition (Figure 1).

Given the relative shortage of empirical data on retailers' assortment composition and size, some of the researchers adopt the descriptive perspective approach. In this approach modelling of assortment decisions of retail outlets is carried out on the basis of empirical results linked to future economic objectives.

At the same time, researchers find it difficult to understand in depth the details of the process of forming assortment groups and subgroups. For this reason, an exploratory descriptive analysis of the choice of assortment size has to be carried out by retailers.

The systematic empirical study of retailers' assortment is becoming a foundation to better understand the assortment variety offered at the different points of sale. This process reflects local demographic characteristics, consumer specificities, proximity to competitive shops and some other factors. It is important to take into account the business activity of intermediaries and the opportunities for sale $(6,9)$.

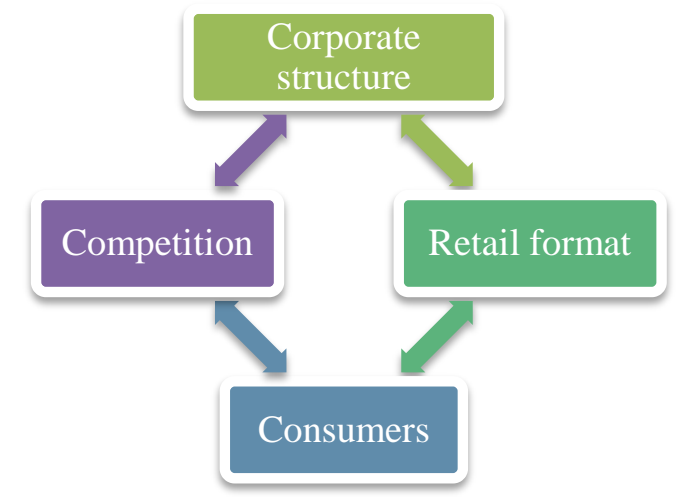

Figure 1. Basic determinants of the choice of assortment size at a point of sale 
For example, if local demand is defined as a key determinant of the choice of assortment size, then how do shops that run their business in the same demographic environment offer similar assortment sizes, regardless of whether they belong to one or another retail chain?

In this aspect, specific demographic characteristics on population growth, age composition and other variables can be taken into account.

The sequence of carrying out the assortment size analysis of certain retailers may include the following integrated steps:

- characterizing corporate structure and retail format - the aim is to clarify the impact of ownership structure and store size on the decisions on the choice of an assortment size;

- describing consumer and competition features as determinants or factors with a certain impact on the establishment of assortment size, including on the costs of securing, maintaining and preserving stock at the corporate level.

Summarizing the power of impact of the determined factors should explain the variations in the assortment size of the analyzed retailers. The assortment size offered by the retail chains operating on the Bulgarian market can be studied in the following order, namely:

- highlighting indicators of sales revenue and profit, their absolute dimensions, relative changes, growth rates;

- analyzing and evaluating the dependence of assortment size on the main determinants and factor conditions describing the elements of the surrounding business environment, such as: consumers with their local demographic characteristics; retail chains with their adjoining corporate ownership and stores' retail format; competition and nature of market rivalry, the proximity to competitive points of sale.

For their part, the determinants as a system and separately outline the context in which the studied retailers are created and compete; the goals of the owners and the managers are taken into account, outlining the impacts on the size of the assortment of goods and services offered. Instead of directly analyzing the assortment size, an approach is applied in which the research interest focuses on the premodelled similarity in the assortment of the stores included in the studied retail chains.
Thus, for example, the adopted assumption is that if local market demand is a key factor in assortment size, then chain stores facing local demographic conditions similar in power of impact should offer similar assortment positions. This approach can be partly adopted because the number of possible assortment combinations increases exponentially in relation to the number of goods. At the same time, the increase in the number of assortment similarities is important.

It is important to analyze the variation and fluctuations occurring in the assortment size. Respecting the results of the retail practice studies published in the specialized literature data is provided allowing variance decomposition. On the basis of analyzing the changes in certain large commodity groups, Chernev, $A$. and $R$. Hamilton find that the corporate structure and store size account for between $25-49 \%$ of the differences in assortment size, while consumer and competition variables account for $7-8 \%$ of the variance (5). This means that the stores' structures of ownership and retail format are of a higher order in clarifying the differences in the assortment size rather than the effects of consumers or competitors.

Generalizing the results of the analysis of similarities and differences in the assortment size allows evaluating and controlling the previous and future sensitivity to the determinants and the factor conditions predetermining its condition.

The following part of this paper uses a set of data relating to the business activity of retail chains operating on the Bulgarian market. These data ensure to a certain extent the investigation and studying of the determinants of choice of assortment size.

\section{EMPIRICAL RESEARCH OF DETERMINANTS OF CHOICE OF ASSORTMENT SIZE}

The empirical database of this study includes information from the retail chains' official sites, data from annual activity reports, as well as data from basic economic performance relating to stores that are part of the common corporate ownership. The study also uses data regularly collected by the National Statistical Institute (NSI) and relating to grocery retailers, based on their annual accounting and bookkeeping data. The NSI presents statistical data on enterprises that are classified in sector $G$ "Trade; repair of motor vehicles and 
motorcycles" under the Classification of Economic Activities. Commodity specialization of retail outlets is taken into account, which is determined according to the prevailing assortment of goods for sale. In its entirety, the set of data formed on the business activity of grocery retailers contributes to the study conducted in this paper (Table 1).

As an object of research in this part of the present study are identified two of the biggest and fast growing retail chains on the Bulgarian market "Billa Bulgaria" EOOD and "Kaufland Bulgaria" $\mathrm{KD}$, which form rich and varied assortment composition and size of grocery and other goods offered.

"Billa" is the first international chain of stores, owned by the Austrian company REWE International AG, which has been on the Bulgarian market since 2000. Currently, Billa Bulgaria EOOD has 126 stores in 38 cities in the country - Sofia, Varna, Burgas, Plovdiv, Stara Zagora, Ruse, etc. The chosen strategy of retail format is "supermarkets", with the staff employed being about 5000 people.

As the manager of "Billa Bulgaria" EOOD reports, the retail company also enters towns having less than 20,000 inhabitants, along with following the strategy of opening stores in Sofia and other big cities - Plovdiv, Varna, Burgas.

The second retail chain studied here is "Kaufland" and it was created in Germany. In 2006 "Kaufland Bulgaria" KD opened its first outlet in the country and 13 years later it already has 59 hypermarkets in 34 towns in Bulgaria. The average retail area of each chain store is
PETROVA S. about 3,500 square metres. According to data of the company, since 2006 it has invested over BGN 1.4 billion in the country, including expanding its warehouses and logistics complexes, with the staff employed being more than 6400 people.

As confirmed by the chairman of the management board of "Kaufland Bulgaria" $\mathrm{KD}$, over the past three years the business priorities of the chain stores have been on developing the existing retail outlets. During their modernization, different concept prototypes have been developed and tested in the hypermarkets. Opportunities for increasing the assortment size offered are sought while keeping the most wanted items, but expanding the portfolio of goods for meeting specific tastes in a higher category. The introduction of its own brands of food, cosmetics and textiles is under way. The activity includes active advertising communication and diversification of commodity mix. The objective is to sustainably develop the leading position on realized sales revenue. Being one of the strongest on the market, the retail company changes the business model followed from retailing to creating brands and experiences. A category of a new type of consumers preferring eco-friendly food is formed, which is a reflection of the dynamic modernization and modification trends $(2,3)$.

Table 1. Absolute size and change in sales revenue and profit of retail chain "Billa Bulgaria" EOOD and retail chain "Kaufland Bulgaria" KD in the period 2015-2017.

\begin{tabular}{|c|c|c|}
\hline Retail chain performance indicators & 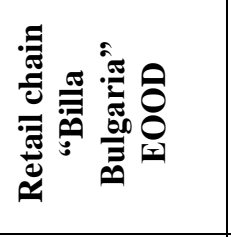 & 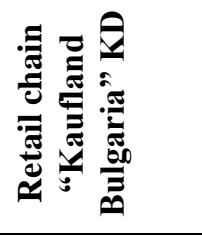 \\
\hline Columns & 1 & 2 \\
\hline Sales revenue in 2015 (thousand BGN) & 575926 & 1488954 \\
\hline Sales revenue in 2016 (thousand BGN) & 662756 & 1667418 \\
\hline Sales revenue in 2017 (thousand BGN) & 724070 & 1739810 \\
\hline Profit in 2015 (thousand BGN) & 4403 & 81821 \\
\hline Profit in 2016 (thousand BGN) & 5424 & 88045 \\
\hline Profit in 2017 (thousand BGN) & 4425 & 79798 \\
\hline Sales revenue profitability in 2017 (in \%) & 0.61 & 4.59 \\
\hline Change in sales revenue in 2017 compared to 2016 (in \%) & 9.25 & 4.34 \\
\hline Change in profit in 2017 compared to 2016 (in \%) & -18.42 & -9.37 \\
\hline Growth rate of sales revenue in 2016 compared to 2015 (in \%) & 15.08 & 11.99 \\
\hline Growth rate of sales revenue in 2017 compared to 2016 (in \%) & 9.25 & 4.34 \\
\hline
\end{tabular}

Source: https://www.capital.bg/K100_2018_top30_retail 
In 2017, the total relative share of sales revenue of the two studied retail chains "Billa Bulgaria" EOOD and "Kaufland Bulgaria" KD, amounted to more than $38 \%$, with a total retail market valuation of BGN 6.5 billion (8). As the data from Table 1 shows, during the analyzed period 2015-2017 the revenue of the analyzed retail companies in absolute value marked an increase. At the same time, the statistical analysis of the development rate of the measured value, related to the characteristics of the growth rate of the sales revenue, allows finding out that both retail companies report a decrease in the dimensioned relative value of the dynamics. As the data from Table 1 shows, during the sub-period 2016-2017 compared to the previous sub-period - 2015-2016, the growth rate of sales revenue of "Billa Bulgaria" EOOD dropped by 5.83 points compared to the 7.65 points of its competitor retail chain. Therefore, in the following years, sales growth forecasts are likely to be more moderate and limited.

Studies of consumer behaviour and the frequency of visit to retail outlets show that in Bulgaria consumers visit a supermarket 11 times a month and a hypermarket -7 times, i.e. the larger retail formats, having significant and optimally built shelf spaces, enjoy an advantageous position (13).

The studied retailers use concepts for looking for additional sales growth opportunities, which are reflected in a variety of innovative ideas assessing consumer requirements.

In its entirety, the reported results regarding realized sales revenue and profits are conditioned by the variance and fluctuations occurring in the assortment offers of the two competing retail chains studied. It is important to do variance decomposition of the assortment size, taking into account the view that the ownership structures and retail format of "Billa Bulgaria" EOOD and "Kaufland Bulgaria" KD predetermine the differences in assortment more significantly than the other determining factors, such as consumers and competitors. This means that the ownership structures and retail format of the stores are of a higher order in clarifying the differences in assortment size than the effects of consumers or competitors.

In this way the empirical research provides evidence of the interrelationships between the basic determinants of choice of assortment size at the point of sale, differentiated in this study such as: corporate structure, retail format, consumers and competition.

\section{CONCLUSIONS AND \\ RECOMMENDATIONS}

Based on this study the following important conclusions can be drawn:

First, in the context of a dynamically changing market environment, the significance of the choice of assortment size by modern retailers increases, ensuring the obtaining of highly effective results from the activity.

Second, the use of an appropriate set of data covering grocery retailers allows us to study the determinants of choice of assortment size highlighting the fact that corporate structure and retail format have a stronger direct relationship with the changes in the assortment size than the influence of consumers and competition.

On the whole, the choice of assortment size made by retailers should be analyzed, collated and evaluated so as to highlight the relative similarities and differences, which will allow the finding out to a certain degree of the manifesting power of impact and effects of the determining factors on assortment offer.

\section{REFERENCES}

1. Arnold, S., T. Oom and D. Tigert. Determinant Attributes in Retail Patronage: Seasonal, Temporal, Regional and International Comparisons. Journal of Marketing Research, 20 (May), pp. 149-157, 1983.

2. Blazheva, V. Challenges facing the EU Common Agricultural Policy, Proceedings of the International Jubilee Scientific Conference "Economy and Management in the XXI century - solutions for stability and growth", Volume 4, Svishtov, pp. 284-288, 2011.

3. Blazheva, V. Regional and global manifestations of trading with agricultural produce, Proceedings of Roundtable with international participation "Commerce and tourism under conditions of smart, sustainable and inclusive growth", Volume II, Svishtov, pp. 203-207, 2016.

4. Broniarczyk, S., D. Hoyner and L. McAlister. Consumers' Perceptions of the Assortment Offered in a Grocery Category: The Impact of Item Reduction. Journal of Marketing 
Research, 35 (May), pp. 166-176, 1998.

5. Chernev, A. and R. Hamilton. Assortment Size and Option Attractiveness in Consumer Choice Among Retailers. Journal of Marketing Research, pp. 410-420, 2009.

6. Filipova, T. Commercial brokerage in transactions with receivables (economic and managerial aspects, fragmentary approbation). Tsenov Academic Publishing house, Svishtov, pp. 9-23, 2009.

7. Fox, E., A. Montgomery, L. Lodish. Consumer Shopping and Spending Across Retail Formats. Journal of Business, 77 (2), pp. 25-26, 2004.

8. Georgieva, M. Bulgarians visit a supermarket 11 times a month and a hypermarket 7 times a month. Regal. 2018.
9. Iliychovski, S. Commercial lending (economic and managerial aspects). Tsenov Academic Publishing House, Svishtov, pp. 63-76, 2008.

10. Kahn, B. and D. Lehmann. Modelling Choice among Assortments. Journal of Retailing, 67 (Fall), pp. 274-299, 1991.

11. Kok, A. and M. Fisher. Demand Estimation and Assortment Optimization under Substitution: Methodology and Application. Operation Research, 55 (6), pp. 10011021, 2007.

12. Midova, P. Management of retail outlets. Tsenov Academic Publishing House, Svishtov, pp. 10-19, 2007.

13. Perkov, V. Trade Modelling (application of mathematical methods and models in trade activities), $\mathrm{V}$. Aprilov University Publishing House, Gabrovo, pp. 119-133, 2018. 